\title{
Advancements in the Diagnosis of Gastric Subepithelial Tumors
}

\author{
Osamu Goto, Mitsuru Kaise, and Katsuhiko Iwakiri \\ Department of Gastroenterology, Graduate School of Medicine, Nippon Medical School, Tokyo, Japan
}

\author{
Article Info \\ Received May 28, 2021 \\ Revised June 29, 2021 \\ Accepted July 6, 2021 \\ Published online August 31, 2021

\section{Corresponding Author}

\section{Osamu Goto} \\ ORCID https://orcid.org/0000-0002-1039-6323 \\ E-mail o-goto@nms.ac.jp
}

\begin{abstract}
A diagnosis of subepithelial tumors (SETs) is sometimes difficult due to the existence of overlying mucosa on the lesions, which hampers optical diagnosis by conventional endoscopy and tissue sampling with standard biopsy forceps. Imaging modalities, by using computed tomography and endoscopic ultrasonography (EUS) are mandatory to noninvasively collect the target's information and to opt candidates for further evaluation. Particularly, EUS is an indispensable diagnostic modality for assessing the lesions precisely and evaluating the possibility of malignancy. The diagnostic ability of EUS appears increased by the combined use of contrast-enhancement or elastography. Histology is the gold standard for obtaining the final diagnosis. Tissue sampling requires special techniques to break the mucosal barrier. Although EUS-guided fine-needle aspiration (EUS-FNA) is commonly applied, mucosal cutting biopsy and mucosal incision-assisted biopsy are comparable methods to definitively obtain tissues from the exposed surface of lesions and seem more useful than EUS-FNA for small SETs. Recent advancements in artificial intelligence (AI) have a potential to drastically change the diagnostic strategy for SETs. Development and establishment of noninvasive methods including Al-assisted diagnosis are expected to provide an alternative to invasive, histological diagnosis. (Gut Liver 2022;16:321-330)
\end{abstract}

Key Words: Subepithelial tumor; Endosonography; Gastrointestinal stromal tumor

\section{INTRODUCTION}

Due to understanding of clinical utility in less-invasiveness of flexible endoscopy, the number of patients who undergo endoscopy is increasing for diagnosis of symptomatic gastrointestinal disorders and surveillance for asymptomatic malignancy. In this situation, the number of gastric subepithelial tumors (SETs) that are accidentally found has been increased. ${ }^{1,2}$ Asymptomatic SETs are revealed as small, unulcered, slightly elevated lesions covered with normal mucosa. Although most small SETs grow slowly, ${ }^{3,4}$ and therefore are considered clinically irrelevant, some of them, e.g., gastrointestinal stromal tumors (GISTs), have malignant potential. Furthermore, high-risk GISTs can quickly become enlarged, metastasize, and take the host's life. Therefore, it seems that SETs are regarded as "nuisances" in clinical situations.

One reason for being hard-to-manage is difficulty in the differential diagnosis of SETs, particularly small lesions. It is considered that SETs that are diagnosed as GIST should be surgically removed as a potential malignant lesion, ${ }^{5-8}$ although there is a slight discordance worldwide according to tumor size, existence of symptoms, and so forth. Therefore, to diagnose whether SETs are GIST is a key to lead the patients to an accurate treatment strategy. However, due to the innate characteristics of a "buried" lesion, a reliable diagnosis of GIST is still difficult to make preoperatively.

The diagnostic strategy of SETs in conventional endoscopy has already been detailed in a previous complete review with massive references. ${ }^{9}$ In this review, we introduce further diagnostic techniques after finding SETs in endoscopy, regarding computed tomography (CT), endoscopic ultrasonography (EUS), histology sampling, and other developing modalities.

\section{EVIDENCE COLLECTION}

This is a narrative review with systematically collected evidence relevant to each topic. The references issued by 
the end of March 2021 were searched via PubMed (http:// www.ncbi.nlm.nih.gov/pubmed), first by using the following keywords; "submucosal tumor" or "subepithelial tumor" or "submucosal lesion" or "subepithelial lesion" for the identification of SETs, and "gastric" or "stomach" for the identification of organ. Subsequently, the following keywords were added for each topic; "computed tomography" or "CT"; "endoscopic ultrasonography" or "echoendoscope" or "endoscopic ultrasound," and "diagnostic ability"; "contrast-enhanced EUS"; "elastography"; "EUS-guided fine-needle aspiration (EUS-FNA)" or "EUS-guided fineneedle biopsy (EUS-FNB)" or "EUS-guided fine-needle aspiration/biopsy (FNAB)"; "mucosal cutting" or "mucosal incision." After excluding case reports/series in less than 10 cases and non-English manuscripts, a single reviewer (O.G.) finally selected to relevant articles by reading them and, if necessary, added papers that were slipped from the search. In terms of the latest topics, references were picked up by a hand search.

\section{COMPUTED TOMOGRAPHY}

$\mathrm{CT}$ is the most accessible imaging modality to investigate abdominal abnormalities including gastric SETs. CT findings provide us reproducible images as well as an objective imaging diagnosis. Simultaneous use of a contrast medium enhances the obtained images and increased information of target lesions. In cases of tumors having a malignant potential, CT can also show whether metastases far from the primary site or invasion into the adjacent organs exist.

However, in close observation of the primary lesions, some previous papers reveal that CT underperform EUS particularly in small SETs. In a retrospective analysis regarding the detectability of CT for possible GISTs of $2 \mathrm{~cm}$ in mean size, sensitivity and specificity in CT are $80.6 \%$ and $84.2 \%$, respectively, when EUS findings are used as a reference. ${ }^{10}$ Furthermore, the detectability of CT is significantly decreased as lesions become small, as showing that the mean sizes of possible GISTs detected and not detected by CT are 27.4 and $11.0 \mathrm{~mm}$, respectively. Another retrospective study in 70 cases also demonstrates low discriminability of CT for SETs less than $10 \mathrm{~mm} .{ }^{11}$ A presumptive diagnosis of histology in CT is far difficult and inferior to that in EUS. A retrospective analysis in 53 SETs reveals that overall accuracy of CT in histology is 50.9\%: $74.2 \%$ in GISTs, $0 \%$ in leiomyoma, and $14.3 \%$ in ectopic pancreas, each of which is lower than that of EUS. ${ }^{12}$

Consequently, CT is useful to obtain general information on lesions and surrounding circumstances as well as the metastases/invasion, however, that is less helpful, particularly in small lesions and suggests equivocal diagnosis in histology.

\section{ENDOSCOPIC ULTRASONOGRAPHY}

In imaging diagnosis of SETs, EUS has the priority. By attaching an echo probe to the surface of lesions with or without water immersion, SETs can be clearly visualized at the closest distance. EUS images provide characteristics of lesions, e.g., location, size, shape, internal echo pattern and the heterogeneity, growth direction, and vascularity, by which we can assess histology and even malignant potential, although obtained images are unfortunately monochrome. The above-mentioned previous studies show favorable diagnostic ability of EUS in both detection and histological estimation, ${ }^{10-12}$ and therefore EUS is a gold standard imaging modality in terms of accessibility, detectability and less invasiveness. Furthermore, the following additional techniques have a potential of enhancing the diagnostic ability in EUS.

\section{CONTRAST-ENHANCED EUS}

The usefulness of contrast-enhanced transabdominal ultrasonography has been acknowledged mainly in the field of hepatology. Likewise, contrast-enhanced EUS (CEEUS) is applied to gastric SETs. ${ }^{13-16}$ A contrast medium, SonoVue (Bracco SpA., Milan, Italy) or Sonazoid (DaiichiSankyo, Tokyo, Japan), includes microbubbles containing carbon dioxide gas with a lipophilic shell. These bubbles are oscillated by the acoustic stimuli, resulting in the enhancement of echo levels in target tissues. In CE-EUS, an optimal amount of the contrast medium is intravenously injected in the observation of EUS. Subsequently, changes of echogenicity are observed. The contrast agent flows into the lesion within 20 seconds, and the dynamic changes are prolonged until a minute.

The potential usefulness of CE-EUS for discriminating GIST from benign SETs was first reported in 2012. ${ }^{13}$ In this pilot study in 17 lesions (29.4 $\mathrm{mm}$ in mean size), all eight GISTs showed hyperenhancement by CE-EUS whereas lipoma and leiomyoma revealed hypoenhanced lesions. In a multicenter analysis in 62 cases, which included relatively large GISTs ( $62.6 \mathrm{~mm}$ in mean size), the diagnostic accuracy was $98 \%$ when hyperenhancement in CE-EUS was regarded as GIST. ${ }^{14}$ Kamata et al. ${ }^{15}$ focused on hyperenhancement and homogeneity of enhancement as the characteristics of GIST. In a retrospective analysis in 
58 GISTs, hyperenhancement was observed in $84.5 \%$ and the diagnostic accuracy was $82.2 \%$ when that was positive for GIST. In contrast, heterogeneous enhancement was present in $36.2 \%$, and the accuracy was $46.6 \%$ when that was used for the indicator of GIST. These findings suggest that the presence of hyperenhancement in CE-EUS is more useful for discriminating GISTs compared to that of heterogeneous enhancement. In these diagnostic analyses by using CE-EUS, the degree of enhancement is subjectively determined by the observer, which may lack reproducibility. Further evaluation is expected to strengthen the utility of this less-invasive approach for discriminating GISTs.

\section{EUS ELASTOGRAPHY}

Elastography is an add-on diagnostic tool to ultrasonography, the utility of which has been demonstrated in the field of hepatic diseases. Recently, several studies suggest that EUS elastography is useful to the differentiation of pancreatic lesions, and it has also been applied to gastrointestinal SETs. ${ }^{14,17,18}$ Elastography represents the stiffness of target lesions, by showing a color spectrum, in which the lesion is shown red, yellow, green, to blue as the lesion is soft to hard accordingly (Fig. 1).

The first pilot study regarding the usefulness of EUS elastography for the differentiation in consecutive 25 gastric SETs revealed that GISTs were harder than other SETs qualitatively by scoring the stiffness referring to the majority and the distribution of the color. ${ }^{17} \mathrm{~A}$ following study indicated that GISTs tended to show blue $(61 / 62,98 \%)$ as the previous study demonstrated, however, this tendency was similar to that in leiomyoma $(4 / 5,80 \%) .{ }^{14} \mathrm{~A}$ recent report, in which a strain ratio was used as an objective indicator, suggested that GIST (the strain ratio, 51.1) could be differentiated from leiomyoma (the strain ratio, 6.0) with favorable sensitivity and specificity. ${ }^{18}$ However, the differentiation of GIST from schwannoma, which is another mesenchymal tumor representing similar visualization to GIST, seems still difficult, considering the strain ratio of schwannoma is 62.0 .

Consequently, EUS elastography is considered a promising less-invasive diagnostic modality, and will be more reliable when using an objective scale e.g., a strain ratio than subjective ones by using the color spectrum. However, the complete discrimination of GIST from other SETs remains
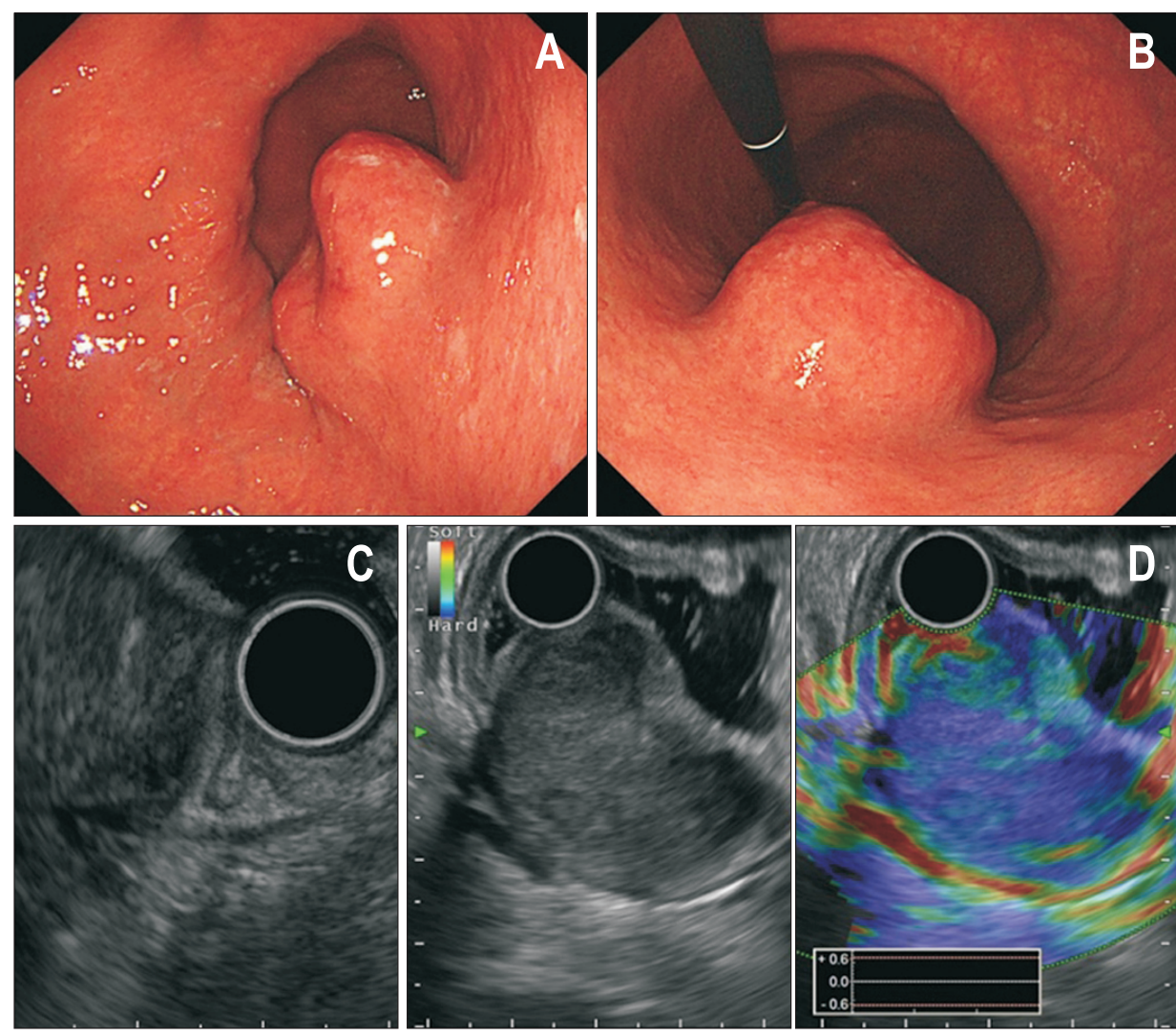

Fig. 1. Elastography in endoscopic ultrasonography. (A) A subepithelial tumor is located on the posterior wall at the middle third of the stomach. (B) A retroflex view. (C) The lesion is connected with the muscular layer. (D) Elastography shows the tumor in blue, which implies that the lesion is hard. Histology reveals a gastrointestinal stromal tumor. 
difficult in a single use of elastography.

\section{EUS-GUIDED FINE-NEEDLE ASPIRATION/BIOPSY}

The gold standard in the diagnosis of tumors is histology. Unlike epithelial tumors, SETs have a possibility of sampling errors in standard biopsy due to a "shield" of normal mucosa, ${ }^{19}$ even though boring biopsy or bite-on-bite biopsy, which involves multiple biopsies at the same point to take deeper tissues in the target lesion, is performed. ${ }^{20}$ The diagnostic yield of these simple biopsy techniques is generally $30 \%$ to $40 \%$, which appears enough disappointing, whereas "unroofing" of the subepithelial lesions by using jumbo biopsy forceps may increase the probability of diagnosis. $^{21}$

In obtaining tissues of SETs, EUS-guided fine-needle aspiration/biopsy (EUS-FNAB) has been accepted as a standard technique (Fig. 2). This method was formerly established to sample pancreatic lesions or extraluminal masses through the overlying gastrointestinal wall. Similarly, tissue sampling is enabled by EUS-FNAB through the overlying mucosa on the subepithelial lesions, although tissues of gastric SET tend to be difficult to obtain compared to pancreatic tumors, probably because of the stiffness and unsteadiness of the lesions. Particularly in intraluminallygrowing hard SETs, the tip of endoscope departs from the target in tapping the lesion, resulting in insufficient puncture. Therefore, technical tips and a certain amount of experience are required in EUS-FNAB for gastric SETs.

Massive studies have already been published regarding the diagnostic yield of EUS-FNAB. ${ }^{22-56}$ A meta-analysis published in 2016 reports that EUS-guided sampling of upper gastrointestinal subepithelial lesions is safe, but has a moderate diagnostic ability (59.9\%) regardless of techniques of FNA/FNB/Tru-Cut needle biopsy or the needle diameter used for puncture. ${ }^{57}$ Conversely, a successive meta-analysis reveals that sampling ability of FNA (80.6\%) is significantly lower to that of FNB (94.9\%), but increase with the help of rapid on-site evaluation. ${ }^{58}$ The discrepancy of results between these two meta-analyses seems to be due to a difference in the heterogeneity of selected studies, development of puncture needles, and accumulation of evidence during the period between the assessments.

In terms of safety of EUS-FNA for gastric SETs, a large-
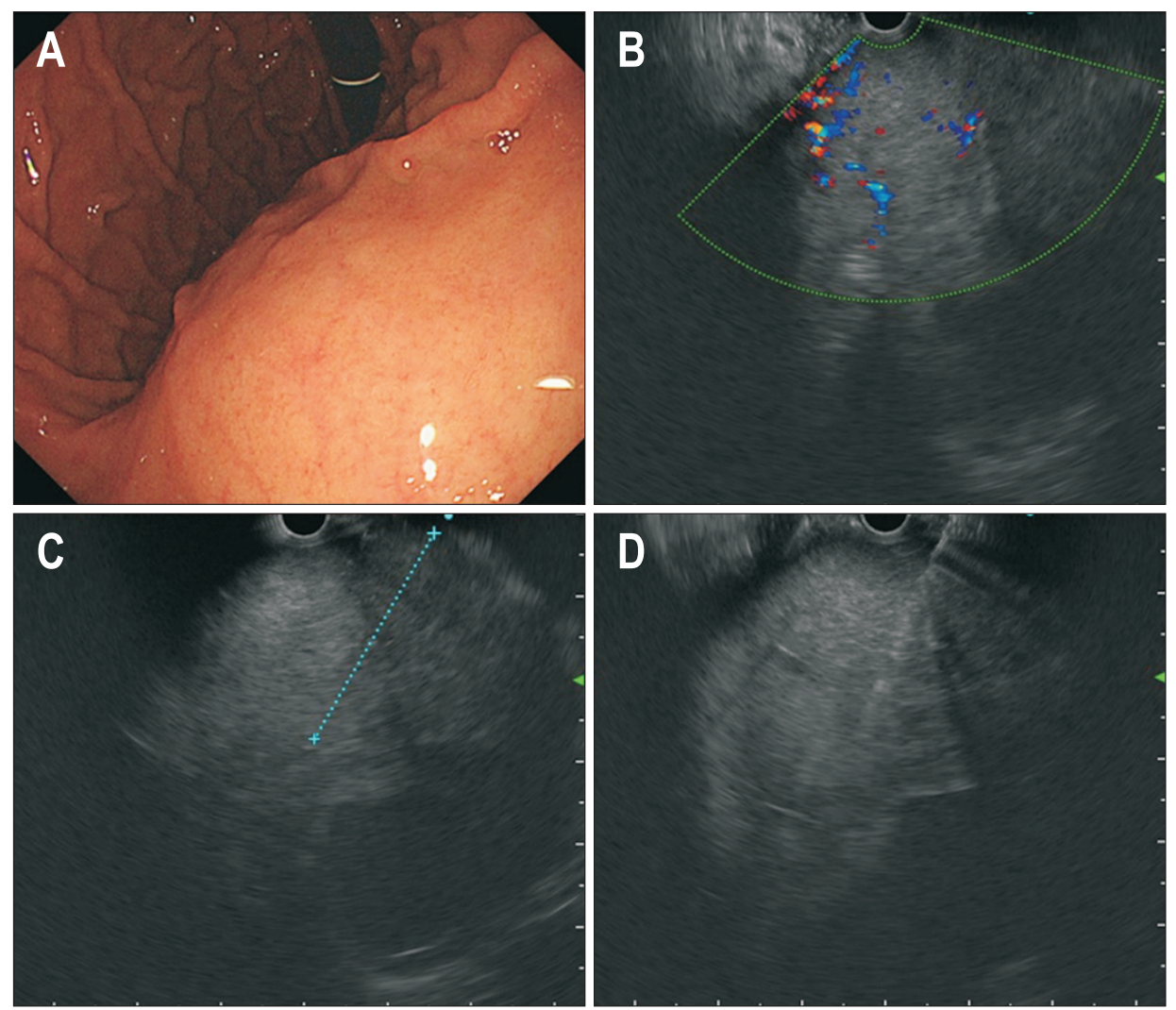

Fig. 2. Endoscopic ultrasonography-guided fine-needle aspiration. (A) A gian subepithelial tumor is on the posterior wall of the gastric body. (B) By using a convex-type echoendoscope, blood flows inside and around the lesion are checked before the procedure. (C) An assumed needle insertion route is indicated. (D) The needle is inserted into the tumor. The tissues are aspirated by jiggling the tip of the needle under negative pressure. 
numbered, multicenter survey demonstrates extremely low risks of bleeding $(4 / 874,0.46 \%)$ and perforation $(0 / 874$, $0 \%){ }^{34}$ Causes of inadequate tissue sampling are analyzed in a single-center, retrospective study, which suggests that age under 60 years and location of lesions at the lower third of the stomach are influential factors on the failure of sufficient tissue sampling, possibly due to stronger gag reflex and difficulty in stabilizing the endoscope. ${ }^{32}$ Small lesions also hamper successful sampling as mentioned in the next topic.

A forward-viewing echoendoscope appears advantages in obtained sample volume and procedure time over a conventional EUS scope ${ }^{36}$ A drill-type sampling device may also be useful in obtaining larger submucosal tissues, ${ }^{41}$ although the postoperative risks should be further investigated. In skill acquisition of EUS-FNA, comparable outcomes are obtained in novice endoscopists under expert's supervision. ${ }^{42}$

In summary, EUS-FNA is the first-line technique in obtaining tissue samples for histology of gastric SETs with low risks of postprocedural adverse events. The diagnostic yield will increase when choosing EUS-FNB and performing rapid on-site evaluation. However, it will be less effective on the histological diagnosis for less than $2 \mathrm{~cm}$ of small lesions.

\section{MUCOSAL CUTTING BIOPSY/MUCOSAL INCISION-ASSISTED BIOPSY}

To expose the surface of lesions by cutting the overlying mucosa using electrocautery is considered to increase the technical success of tissue sampling because the exposure of the tumor surface enables target biopsies under the direct visualization of the tissues (Fig. 3). The usefulness of this technique, termed mucosal cutting biopsy (MCB) or mucosal incision-assisted biopsy (MIAB), has been reported in several articles (Table 1), ${ }^{59-69}$ many of which are retrospective, single-arm analyses with a relatively small number of cases. In approximately $20 \mathrm{~mm}$ in size, the diagnostic yield of MCB/MIAB for gastric SETs shows $86.9 \%$ in 314 lesions, ranging from $60 \%$ to $100 \%$ among the articles. The procedure time required for $\mathrm{MCB} / \mathrm{MIAB}$ varies, which seems to be affected by the number of samples and the degree of endoscopist's confidence that the tissue is surely obtained. Perforation and delayed bleeding, major adverse events in this technique, is $0.3 \%$ each, which is extremely low. One randomized controlled study between $\mathrm{MCB} /$ MIAB and EUS-FNA demonstrates higher diagnostic ability at the crossover phase, longer procedure time, and larger sample number in $\mathrm{MCB} / \mathrm{MIAB}$ than EUS-FNA. ${ }^{65}$
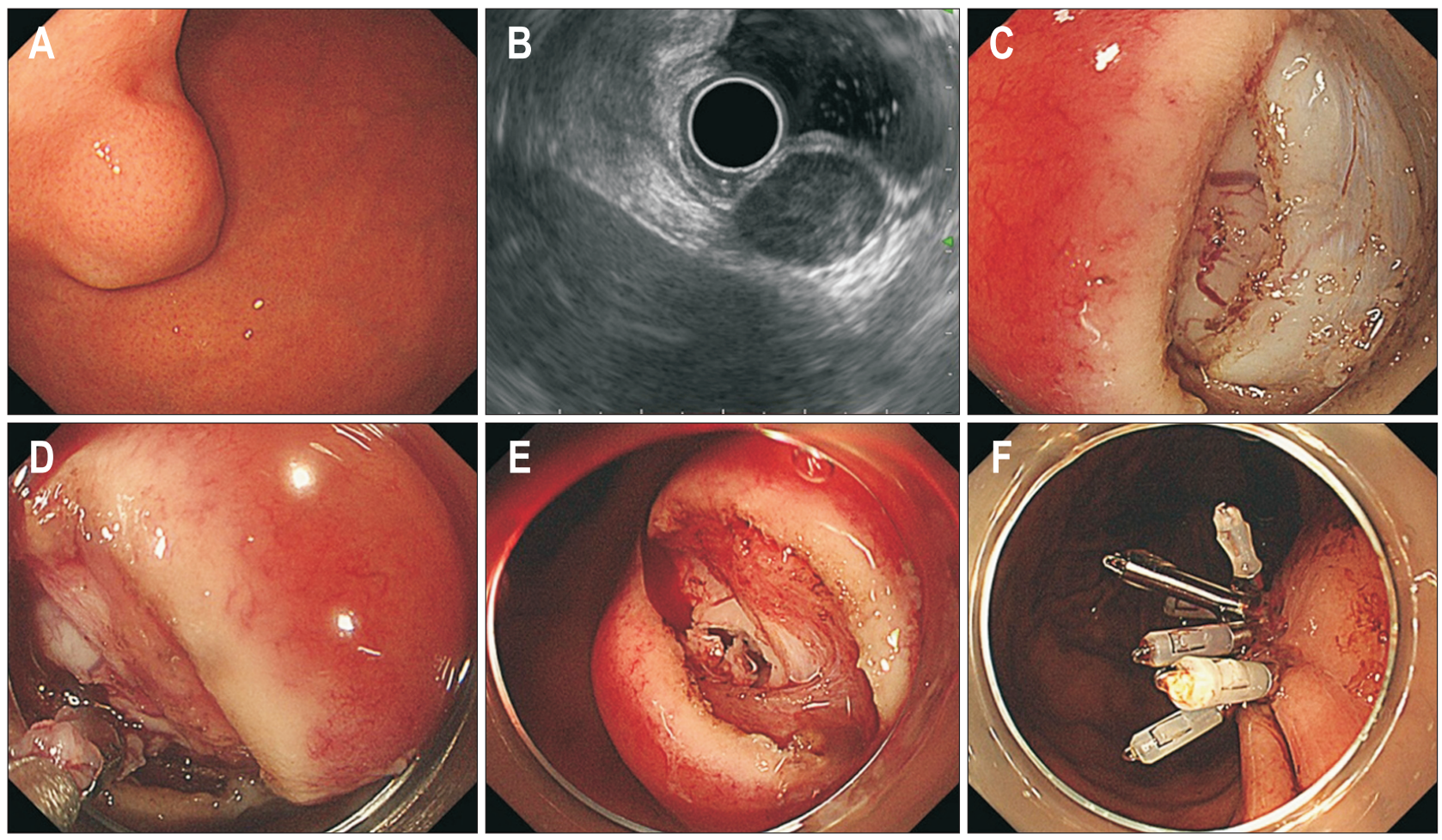

Fig. 3. Mucosal cutting biopsy/mucosal incision-assisted biopsy. (A) An intraluminally growing type of subepithelial lesion is on the anterior wall at the gastric angle. (B) Endoscopic ultrasonography (EUS) shows a hypoechoic mass arising from the fourth layer. The size of less than $2 \mathrm{~cm}$ and the presence of the liver just behind the lesion hamper a safe and successful EUS-guided fine-needle biopsy. (C) Mucosal incision enables exposure of the surface of the submucosal lesion. (D) Biopsies are taken under the direct visualization of the tumor. (E) The tumor is certainly sampled by several biopsies. (F) The incised mucosa is closed with clips. 
Table 1. Published Articles on Mucosal Cutting Biopsy/Mucosal Incision-Assisted Biopsy

\begin{tabular}{|c|c|c|c|c|c|c|}
\hline Author (year) & No. & Design & $\begin{array}{l}\text { Size, } \\
\mathrm{mm}\end{array}$ & $\begin{array}{l}\text { Diagnostic } \\
\text { yield, \%* }\end{array}$ & $\begin{array}{l}\text { Procedure } \\
\text { time, min }\end{array}$ & $\begin{array}{c}\text { Adverse } \\
\text { events, } \%^{\dagger}\end{array}$ \\
\hline Kataoka et al. $(2013)^{59}$ & 18 & Retrospective, single-arm & 20.3 & 100 & $15-30$ & 0 \\
\hline Ihara et al. $(2013)^{60}$ & 27 & Retrospective, single-arm & 21.2 & 85 & 32 & 0 \\
\hline Kim et al. $(2013)^{61}$ & 11 & Retrospective, single-arm & 21.8 & 91 & 9 & 0 \\
\hline Ikehara et al. $(2015)^{62}$ & 20 & Retrospective, comparative & 23.6 & 60 & NA & 0 \\
\hline Jung et al. $(2016)^{63}$ & 42 & Prospective, single-arm, comparative to historical control & 18.8 & 83 & 10 & 0 \\
\hline Shin et al. $(2017)^{64}$ & 11 & Retrospective, single-arm & 28.5 & 92 & NA & 0 \\
\hline Osoegawa et al. $(2019)^{65}$ & 23 & Prospective, randomized, crossover, multicenter & 20.0 & 91 & 34 & 0 \\
\hline Adachi et al. $(2019)^{66}$ & 16 & Retrospective, comparative & 21.2 & 88 & 41 & 0 \\
\hline Mizukami et al. (2019) ${ }^{67}$ & 30 & Retrospective, single-arm & 15.4 & 93 & NA & 0 \\
\hline Minoda et al. $(2020)^{68}$ & 71 & Retrospective, comparative, multicenter & 19.6 & 94 & 32 & 0 \\
\hline Nakano et al. $(2020)^{69}$ & 45 & Retrospective, single-arm & 20.0 & 78 & 20 & 4 \\
\hline
\end{tabular}

NA, not assessed.

*Suspected cases are included; ${ }^{\dagger}$ Endoscopically-treatable intraoperative bleeding is not included.

In contrast, another retrospective study reveals that $\mathrm{MCB} /$ MIAB requires shorter procedure time than EUS-FNA with a comparative diagnostic yield. ${ }^{63}$ Some papers suggest the characteristics of MCB/MIAB as follows: small and intraluminally-growing type lesions are good indications, ${ }^{61,63}$ immunohistochemistry staining is more easily obtained, ${ }^{67}$ and clear exposure of the surface is important for successful diagnosis. ${ }^{69}$ Consequently, MCB/MIAB has sufficient diagnostic ability and is advantageous over EUS-FNA, particularly in small (less than $2 \mathrm{~cm}$ ), intraluminal growthtype SETs, given that the endoscopists have certain skills to cut the underlying mucosa by using electrocautery devices and to expose the tumor surface enough to confirm where the tumor is. Additionally, endoscopists should be cautious about postprocedural adverse events e.g., perforation or delayed bleeding because the number of clinical cases published is still small compared to EUS-FNAB as the established technique. Furthermore, the potential of tumor growth due to the burning effect is also taken into consideration, although the growth effect has not been clinically demonstrated and seems difficult to elucidate.

\section{OTHERS}

Various diagnostic techniques and modalities for SETs have been further devised and developed. Particularly, clinical use of artificial intelligence (AI) revolutionizes endoscopic diagnosis including SETs. Minoda et al. ${ }^{70}$ reported the usefulness of AI by using EUS images. In 273 SETs including 173 cases for training and 100 cases for the test, AI using deep learning methods demonstrated superior discriminative accuracy of GISTs $(86.3 \%$ in less than $20 \mathrm{~mm}, 90.0 \%$ in $20 \mathrm{~mm}$ or more) to EUS experts. Notably, 4.5 seconds of the diagnostic speed in AI overwhelmed that in experts. Almost simultaneously, Kim et al. ${ }^{71}$ introduced the potential of a convolutional neural network computer-aided diagnosis for differentiation of GIST from non-GIST (accuracy, 79.2\%) as well as for differentiation of leiomyoma from schwannoma (accuracy, 75.5\%) in 179 cases for training and 69 cases for the test. Yang et al. ${ }^{72}$ also investigated the diagnostic ability of AI in EUS images, in which the use of the AI diagnosis had an additional effect in the discrimination of GISTs from leiomyoma to the expert endosonographers' diagnosis by increasing $73.8 \%$ to $88.8 \%$ of the accuracy. Interestingly, this study also reveals that the AI diagnosis by using EUS imaging depends on the choice of EUS probe, and rare SETs other than GISTs or leiomyoma are still difficult to diagnose due to less learning opportunity. Sato et al. ${ }^{73}$ attempted to combine AI with near-infrared hyperspectral imaging, demarcating GISTs buried in the deeper layer from the outside. This exvivo study using surgically-removed GISTs demonstrates the potential ability in clear demarcation of GISTs with a favorable accuracy of $86.1 \%$. The use of AI must be promising in the endoscopic diagnosis as an accurate, speedy and inexhaustible tool, therefore further progresses are expected.

Digital image analysis by using EUS images also seems interesting. ${ }^{74}$ After the standardization of EUS images, brightness and variability of the internal echo pattern are evaluated as indicators of echogenicity and heterogeneity, respectively. This analysis has been attempted by using an artificial neural network ${ }^{75}$ or a hand-made calculator, ${ }^{76,77}$ and these previous studies suggest a potential ability of this method in differentiating GIST from other SETs. After confirming the favorable results in prospective trials, standard equipment of this calculator on a commerciallyavailable EUS system is expected in the future.

Morphological difference can also be a potential indica- 


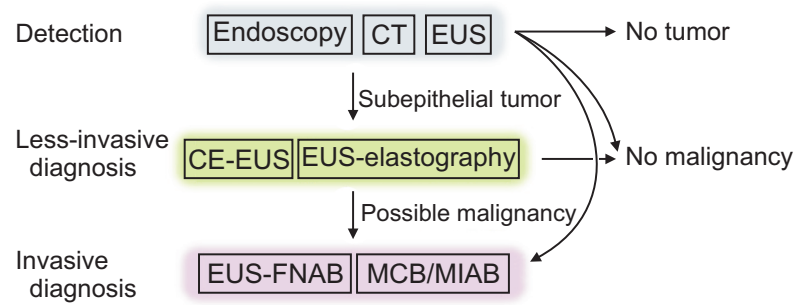

Fig. 4. Diagnostic strategy of subepithelial tumors. After a subepithelial tumor is suspected by standard endoscopy or CT, EUS is conducted to confirm if it is a true tumor. Less-invasive approaches may be useful to assess the potential of malignancy. Finally, tissue sampling is considered for possible malignant lesions to obtain the histological diagnosis.

CT, computed tomography; EUS, endoscopic ultrasonography; CEEUS, contrast-enhancement EUS; EUS-FNAB, EUS-guided fine-needle aspiration/biopsy; MCB/MIAB, mucosal cutting biopsy/mucosal incision-assisted biopsy.

tor to differentiate SETs. As an objective diagnostic measure, circularity, which represents the likeliness of a true circle as a figure from 0 to 1 , seems useful to noninvasively distinguish three types of gastrointestinal mesenchymal tumors, GIST, leiomyoma, and schwannoma. A retrospective pilot study implies that GISTs appear roundish whereas leiomyomas tend to be craggy, and these may be distinguishable by using circularity. ${ }^{78}$ Further evaluation in a larger number of cases is awaited.

\section{CONCLUSIONS AND PERSPECTIVES}

In the diagnosis of SETs, various approaches to the lesions over the epithelium have been devised. By summarizing the above-mentioned techniques, a diagnostic strategy for gastric SETs shown in Fig. 4 is proposed. Asymptomatic SETs are firstly detected by chance with esophagogastroduodenoscopy or CT. Subsequently, EUS is recommended to confirm that the lesion is a true SET because "mimicking SETs" by extraluminal compression is easily unveiled by EUS. Furthermore, some kinds of benign SET e.g., cyst, lipoma, can be diagnosed by conventional EUS by visualizing internal echo levels and patterns. After nominating possible GISTs as potential malignancy, CE-EUS or EUS elastography may be useful as less-invasive approaches to differentiate benign stromal tumors such as leiomyoma or schwannoma. Finally, histological assessments are considered to obtain the final diagnosis and to determine whether it is a candidate for treatment.

There is still room for discussion regarding the indication of surgical resection in small GISTs. Surgery involves risks of perioperative adverse events and post-gastrectomy syndrome. In cases close to the gastric fundus, which is a familiar location for GISTs, local resection is sometimes difficult, and may be switched to extended gastrectomy. Accordingly, surgeons will become reluctant for surgery, particularly in small lesions, considering the balance between risks and benefits. Alternatively, recent advancements of therapeutic endoscopy have enabled minimallyinvasive endoscopic resection as represented by endoscopic full-thickness resection (EFTR)..$^{79}$ Although it is still developing, EFTR is expected to become as an alternative method to conventional surgical resection techniques in the near future. When EFTR is established as the standard treatment method, accurate diagnosis for perorally-retrieval small SETs should become more important. Further investigation and development are expected.

\section{CONFLICTS OF INTEREST}

No potential conflict of interest relevant to this article was reported.

\section{ORCID}

Osamu Goto https://orcid.org/0000-0002-1039-6323

Mitsuru Kaise https://orcid.org/0000-0002-4593-9527

Katsuhiko Iwakiri https://orcid.org/0000-0002-5558-6104

\section{REFERENCES}

1. Papanikolaou IS, Triantafyllou K, Kourikou A, Rösch T. Endoscopic ultrasonography for gastric submucosal lesions. World J Gastrointest Endosc 2011;3:86-94.

2. McCarty TR, Ryou M. Endoscopic diagnosis and management of gastric subepithelial lesions. Curr Opin Gastroenterol 2020;36:530-537.

3. Koizumi S, Kida M, Yamauchi H, et al. Clinical implications of doubling time of gastrointestinal submucosal tumors. World J Gastroenterol 2016;22:10015-10023.

4. Ye LS, Li Y, Liu W, Yao MH, Khan N, Hu B. Clinical course of suspected small gastrointestinal stromal tumors in the stomach. World J Gastrointest Surg 2020;12:171-177.

5. Nishida T, Blay JY, Hirota S, Kitagawa Y, Kang YK. The standard diagnosis, treatment, and follow-up of gastrointestinal stromal tumors based on guidelines. Gastric Cancer 2016;19: 3-14.

6. Nishida T, Goto O, Raut CP, Yahagi N. Diagnostic and treatment strategy for small gastrointestinal stromal tumors. Cancer 2016;122:3110-3118.

7. Koo DH, Ryu MH, Kim KM, et al. Asian consensus guide- 
lines for the diagnosis and management of gastrointestinal stromal tumor. Cancer Res Treat 2016;48:1155-1166.

8. Kadkhodayan K, Rafiq E, Hawes RH. Endoscopic evaluation and management of gastric stromal tumors. Curr Treat Options Gastroenterol 2017;15:691-700.

9. Kim GH. Systematic endoscopic approach for diagnosing gastric subepithelial tumors. Gut Liver 2022;16:19-27.

10. Goto O, Kambe H, Niimi K, et al. Discrepancy in diagnosis of gastric submucosal tumor among esophagogastroduodenoscopy, CT, and endoscopic ultrasonography: a retrospective analysis of 93 consecutive cases. Abdom Imaging 2012; 37:1074-1078.

11. Ra JC, Lee ES, Lee JB, et al. Diagnostic performance of stomach CT compared with endoscopic ultrasonography in diagnosing gastric subepithelial tumors. Abdom Radiol (NY) 2017;42:442-450.

12. Kim SY, Shim KN, Lee JH, et al. Comparison of the diagnostic ability of endoscopic ultrasonography and abdominopelvic computed tomography in the diagnosis of gastric subepithelial tumors. Clin Endosc 2019;52:565-573.

13. Kannengiesser K, Mahlke R, Petersen F, et al. Contrastenhanced harmonic endoscopic ultrasound is able to discriminate benign submucosal lesions from gastrointestinal stromal tumors. Scand J Gastroenterol 2012;47:1515-1520.

14. Ignee A, Jenssen C, Hocke M, et al. Contrast-enhanced (endoscopic) ultrasound and endoscopic ultrasound elastography in gastrointestinal stromal tumors. Endosc Ultrasound 2017;6:55-60.

15. Kamata K, Takenaka M, Kitano M, et al. Contrast-enhanced harmonic endoscopic ultrasonography for differential diagnosis of submucosal tumors of the upper gastrointestinal tract. J Gastroenterol Hepatol 2017;32:1686-1692.

16. Pesenti C, Bories E, Caillol F, et al. Characterization of subepithelial lesions of the stomach and esophagus by contrastenhanced EUS: a retrospective study. Endosc Ultrasound 2019;8:43-49.

17. Tsuji Y, Kusano C, Gotoda T, et al. Diagnostic potential of endoscopic ultrasonography-elastography for gastric submucosal tumors: a pilot study. Dig Endosc 2016;28:173-178.

18. Kim SH, Yoo IK, Kwon CI, Hong SP, Cho JY. Utility of EUS elastography in the diagnosis of gastric subepithelial tumors: a pilot study (with video). Gastrointest Endosc 2020;91:172177.

19. Hunt GC, Smith PP, Faigel DO. Yield of tissue sampling for submucosal lesions evaluated by EUS. Gastrointest Endosc 2003;57:68-72.

20. Ji JS, Lee BI, Choi KY, et al. Diagnostic yield of tissue sampling using a bite-on-bite technique for incidental subepithelial lesions. Korean J Intern Med 2009;24:101-105.

21. Komanduri S, Keefer L, Jakate S. Diagnostic yield of a novel jumbo biopsy "unroofing" technique for tissue acquisition of gastric submucosal masses. Endoscopy 2011;43:849-855.

22. Fu K, Eloubeidi MA, Jhala NC, Jhala D, Chhieng DC, Eltoum IE. Diagnosis of gastrointestinal stromal tumor by endoscopic ultrasound-guided fine needle aspiration biopsy: a potential pitfall. Ann Diagn Pathol 2002;6:294-301.

23. Okubo K, Yamao K, Nakamura T, et al. Endoscopic ultrasound-guided fine-needle aspiration biopsy for the diagnosis of gastrointestinal stromal tumors in the stomach. J Gastroenterol 2004;39:747-753.

24. Chatzipantelis P, Salla C, Karoumpalis I, et al. Endoscopic ultrasound-guided fine needle aspiration biopsy in the diagnosis of gastrointestinal stromal tumors of the stomach: a study of 17 cases. J Gastrointestin Liver Dis 2008;17:15-20.

25. Hoda KM, Rodriguez SA, Faigel DO. EUS-guided sampling of suspected GI stromal tumors. Gastrointest Endosc 2009; 69:1218-1223.

26. Sepe PS, Moparty B, Pitman MB, Saltzman JR, Brugge WR. EUS-guided FNA for the diagnosis of GI stromal cell tumors: sensitivity and cytologic yield. Gastrointest Endosc 2009;70:254-261.

27. Yoshida S, Yamashita K, Yokozawa M, et al. Diagnostic findings of ultrasound-guided fine-needle aspiration cytology for gastrointestinal stromal tumors: proposal of a combined cytology with newly defined features and histology diagnosis. Pathol Int 2009;59:712-719.

28. Mekky MA, Yamao K, Sawaki A, et al. Diagnostic utility of EUS-guided FNA in patients with gastric submucosal tumors. Gastrointest Endosc 2010;71:913-919.

29. Fernández-Esparrach G, Sendino O, Solé M, et al. Endoscopic ultrasound-guided fine-needle aspiration and trucut biopsy in the diagnosis of gastric stromal tumors: a randomized crossover study. Endoscopy 2010;42:292-299.

30. Turhan N, Aydog G, Ozin Y, Cicek B, Kurt M, Oguz D. Endoscopic ultrasonography-guided fine-needle aspiration for diagnosing upper gastrointestinal submucosal lesions: a prospective study of 50 cases. Diagn Cytopathol 2011;39:808817.

31. Watson RR, Binmoeller KF, Hamerski CM, et al. Yield and performance characteristics of endoscopic ultrasoundguided fine needle aspiration for diagnosing upper GI tract stromal tumors. Dig Dis Sci 2011;56:1757-1762.

32. Suzuki T, Arai M, Matsumura T, et al. Factors associated with inadequate tissue yield in EUS-FNA for gastric SMT. ISRN Gastroenterol 2011;2011:619128.

33. Eckardt AJ, Adler A, Gomes EM, et al. Endosonographic large-bore biopsy of gastric subepithelial tumors: a prospective multicenter study. Eur J Gastroenterol Hepatol 2012;24: 1135-1144.

34. Hamada T, Yasunaga H, Nakai Y, et al. Rarity of severe bleeding and perforation in endoscopic ultrasound-guided fine needle aspiration for submucosal tumors. Dig Dis Sci 
2013;58:2634-2638.

35. Kim GH, Cho YK, Kim EY, et al. Comparison of 22-gauge aspiration needle with 22-gauge biopsy needle in endoscopic ultrasonography-guided subepithelial tumor sampling. Scand J Gastroenterol 2014;49:347-354.

36. Matsuzaki I, Miyahara R, Hirooka Y, et al. Forward-viewing versus oblique-viewing echoendoscopes in the diagnosis of upper GI subepithelial lesions with EUS-guided FNA: a prospective, randomized, crossover study. Gastrointest Endosc 2015;82:287-295.

37. Na HK, Lee JH, Park YS, et al. Yields and utility of endoscopic ultrasonography-guided 19-gauge trucut biopsy versus 22-gauge fine needle aspiration for diagnosing gastric subepithelial tumors. Clin Endosc 2015;48:152-157.

38. Lee JH, Cho CJ, Park YS, et al. EUS-guided 22-gauge fine needle biopsy for the diagnosis of gastric subepithelial tumors larger than $2 \mathrm{~cm}$. Scand J Gastroenterol 2016;51:486493.

39. Lee $\mathrm{M}$, Min BH, Lee H, et al. Feasibility and diagnostic yield of endoscopic ultrasonography-guided fine needle biopsy with a new core biopsy needle device in patients with gastric subepithelial tumors. Medicine (Baltimore) 2015;94:e1622.

40. Kim HJ, Jung YS, Park JH, et al. Endosonographer's macroscopic evaluation of EUS-FNAB specimens after interactive cytopathologic training: a single-center prospective validation cohort study. Surg Endosc 2016;30:4184-4192.

41. Walther C, Jeremiasen M, Rissler P, Johansson JL, Larsson MS, Walther BS. A new method for endoscopic sampling of submucosal tissue in the gastrointestinal tract: a comparison of the biopsy forceps and a new drill instrument. Surg Innov 2016;23:572-580.

42. Niimi K, Goto O, Kawakubo K, et al. Endoscopic ultrasound-guided fine-needle aspiration skill acquisition of gastrointestinal submucosal tumor by trainee endoscopists: a pilot study. Endosc Ultrasound 2016;5:157-164.

43. Han JP, Lee TH, Hong SJ, et al. EUS-guided FNA and FNB after on-site cytological evaluation in gastric subepithelial tumors. J Dig Dis 2016;17:582-587.

44. Uesato M, Tamachi T, Hanari N, et al. Drill needle aspiration biopsy for submucosal tumors in an experimental study. Gastric Cancer 2017;20:475-480.

45. El Chafic AH, Loren D, Siddiqui A, Mounzer R, Cosgrove N, Kowalski T. Comparison of FNA and fine-needle biopsy for EUS-guided sampling of suspected GI stromal tumors. Gastrointest Endosc 2017;86:510-515.

46. Iwai T, Kida M, Imaizumi $\mathrm{H}$, et al. Randomized crossover trial comparing EUS-guided fine-needle aspiration with EUS-guided fine-needle biopsy for gastric subepithelial tumors. Diagn Cytopathol 2018;46:228-233.

47. Antonini F, Delconte G, Fuccio L, et al. EUS-guided tissue sampling with a 20 -gauge core biopsy needle for the charac- terization of gastrointestinal subepithelial lesions: a multicenter study. Endosc Ultrasound 2019;8:105-110.

48. Attila T, Aydın Ö. Lesion size determines diagnostic yield of EUS-FNA with onsite cytopathologic evaluation for upper gastrointestinal subepithelial lesions. Turk J Gastroenterol 2018;29:436-441.

49. Khoury T, Kadah A, Farraj M, et al. The role of rapid on-site evaluation on diagnostic accuracy of endoscopic ultrasound fine needle aspiration for pancreatic, submucosal upper gastrointestinal tract and adjacent lesions. Cytopathology 2019; 30:499-503.

50. Sandoh K, Ishida M, Okano K, et al. Utility of endoscopic ultrasound-guided fine-needle aspiration cytology in rapid on-site evaluation for the diagnosis of gastric submucosal tumors: retrospective analysis of a single-center experience. Diagn Cytopathol 2019;47:869-875.

51. Kim GH, Ahn JY, Gong CS, et al. Efficacy of endoscopic ultrasound-guided fine-needle biopsy in gastric subepithelial tumors located in the cardia. Dig Dis Sci 2020;65:583-590.

52. Gilani SM, Muniraj T, Aslanian HR, Cai G. Endoscopic ultrasound-guided fine needle aspiration cytology diagnosis of upper gastrointestinal tract mesenchymal tumors: impact of rapid onsite evaluation and correlation with histopathologic follow-up. Diagn Cytopathol 2021;49:203-210.

53. Kamata K, Kurita A, Yasukawa S, et al. Utility of a $20 \mathrm{G}$ needle with a core trap in EUS-guided fine-needle biopsy for gastric submucosal tumors: a multicentric prospective trial. Endosc Ultrasound 2021;10:134-140.

54. Lopes CV, Hartmann AA, Artifon EL. EUS-FNA with 19 or 22 gauges needles for gastric subepithelial lesions of the muscle layer. Arq Bras Cir Dig 2018;31:e1350.

55. Antonini F, Giorgini S, Fuccio L, Angelelli L, Macarri G. EUS-guided sampling with $25 \mathrm{G}$ biopsy needle as a rescue strategy for diagnosis of small subepithelial lesions of the upper gastrointestinal tract. Endosc Int Open 2018;6:E892E897.

56. de Moura DT, McCarty TR, Jirapinyo P, et al. EUS-guided fine-needle biopsy sampling versus FNA in the diagnosis of subepithelial lesions: a large multicenter study. Gastrointest Endosc 2020;92:108-119.

57. Zhang XC, Li QL, Yu YF, et al. Diagnostic efficacy of endoscopic ultrasound-guided needle sampling for upper gastrointestinal subepithelial lesions: a meta-analysis. Surg Endosc 2016;30:2431-2441.

58. Facciorusso A, Sunny SP, Del Prete V, Antonino M, Muscatiello N. Comparison between fine-needle biopsy and fineneedle aspiration for EUS-guided sampling of subepithelial lesions: a meta-analysis. Gastrointest Endosc 2020;91:14-22.

59. Kataoka M, Kawai T, Yagi K, et al. Mucosal cutting biopsy technique for histological diagnosis of suspected gastrointestinal stromal tumors of the stomach. Dig Endosc 2013;25: 
274-280.

60. Ihara E, Matsuzaka H, Honda K, et al. Mucosal-incision assisted biopsy for suspected gastric gastrointestinal stromal tumors. World J Gastrointest Endosc 2013;5:191-196.

61. Kim JH, Chung JW, Ha M, et al. A feasible modified biopsy method for tissue diagnosis of gastric subepithelial tumors. World J Gastroenterol 2013;19:4752-4757.

62. Ikehara H, Li Z, Watari J, et al. Histological diagnosis of gastric submucosal tumors: a pilot study of endoscopic ultrasonography-guided fine-needle aspiration biopsy vs mucosal cutting biopsy. World J Gastrointest Endosc 2015;7:11421149.

63. Jung YS, Lee H, Kim K, Sohn JH, Kim HJ, Park JH. Using forceps biopsy after small submucosal dissection in the diagnosis of gastric subepithelial tumors. J Korean Med Sci 2016; 31:1768-1774.

64. Shin SY, Lee SJ, Jun JH, et al. Mucosal incision and forceps biopsy for reliable tissue sampling of gastric subepithelial tumors. Clin Endosc 2017;50:64-68.

65. Osoegawa T, Minoda Y, Ihara E, et al. Mucosal incisionassisted biopsy versus endoscopic ultrasound-guided fineneedle aspiration with a rapid on-site evaluation for gastric subepithelial lesions: a randomized cross-over study. Dig Endosc 2019;31:413-421.

66. Adachi A, Hirata Y, Kawamura H, et al. Efficacy of mucosal cutting biopsy for the histopathological diagnosis of gastric submucosal tumors. Case Rep Gastroenterol 2019;13:185194.

67. Mizukami K, Matsunari O, Ogawa R, et al. Examine the availability and safety of mucosal cutting biopsy technique for diagnosis of gastric submucosal tumor. Gastroenterol Res Pract 2019;2019:3121695.

68. Minoda Y, Chinen T, Osoegawa T, et al. Superiority of mucosal incision-assisted biopsy over ultrasound-guided fine needle aspiration biopsy in diagnosing small gastric subepithelial lesions: a propensity score matching analysis. BMC Gastroenterol 2020;20:19.

69. Nakano Y, Takao T, Morita Y, et al. Reasons for diagnostic failure in forty-five consecutive mucosal cutting biopsy examinations of gastric subepithelial tumors. Clin Endosc 2020;53:575-582.

70. Minoda Y, Ihara E, Komori K, et al. Efficacy of endoscopic ultrasound with artificial intelligence for the diagnosis of gastrointestinal stromal tumors. J Gastroenterol 2020;55: 1119-1126.

71. Kim YH, Kim GH, Kim KB, et al. Application of a convolutional neural network in the diagnosis of gastric mesenchymal tumors on endoscopic ultrasonography images. J Clin Med 2020;9:3162.

72. Yang X, Wang H, Dong Q, et al. An artificial intelligence system for distinguishing between gastrointestinal stromal tumors and leiomyomas using endoscopic ultrasonography. Endoscopy 2022;54:251-261.

73. Sato D, Takamatsu T, Umezawa M, et al. Distinction of surgically resected gastrointestinal stromal tumor by nearinfrared hyperspectral imaging. Sci Rep 2020;10:21852.

74. Lee MW, Kim GH. Diagnosing gastric mesenchymal tumors by digital endoscopic ultrasonography image analysis. Clin Endosc 2021;54:324-328.

75. Nguyen VX, Nguyen CC, Li B, Das A. Digital image analysis is a useful adjunct to endoscopic ultrasonographic diagnosis of subepithelial lesions of the gastrointestinal tract. J Ultrasound Med 2010;29:1345-1351.

76. Kim GH, Kim KB, Lee SH, et al. Digital image analysis of endoscopic ultrasonography is helpful in diagnosing gastric mesenchymal tumors. BMC Gastroenterol 2014;14:7.

77. Lee MW, Kim GH, Kim KB, et al. Digital image analysisbased scoring system for endoscopic ultrasonography is useful in predicting gastrointestinal stromal tumors. Gastric Cancer 2019;22:980-987.

78. Goto O, Akimoto T, Koizumi E, et al. Circularity in endoscopic ultrasonography imaging as a useful diagnostic indicator of gastrointestinal stromal tumours: a retrospective analysis in 51 gastric cases. United European Gastroenterol J 2019;7 Suppl 8:AB245-AB246.

79. Chen H, Li B, Li L, et al. Current status of endoscopic resection of gastric subepithelial tumors. Am J Gastroenterol 2019;114:718-725. 